\title{
OCORRÊNCIA DE Frankliniella schultzei (TRYBOM) (THYSANOPTERA: THRIPIDAE) EM PLANTAS DANINHAS ${ }^{1}$
}

\author{
MARIA G. A. LIMA ${ }^{2}$, NILZA M. MARTINELLI ${ }^{3}$ e RENATA C. MONTEIRO ${ }^{4}$
}

\section{RESUMO}

Realizaram-se levantamentos de plantas daninhas, no Campus da UNESP em Jaboticabal/SP, com o objetivo de identificar espécies de plantas daninhas hospedeiras do tripes Frankliniella schultzei (Trybom). As plantas foram coletadas semanalmente utilizando-se o método de ensacamento. A separação dos tripes foi feita mediante emprego do funil de Berlese. Entre as 43 espécies de plantas daninhas encontradas nas áreas amostradas, 19 são hospedeiras do tripes. Rabanete (Raphanus sativus L.), nabiça ( $R$. raphanistrum $L$.) e mostarda (Sinapsis arvensis L.) foram as que apresentaram as maiores porcentagens de $F$. schultzei, 45, $27 \mathrm{e}$ $17 \%$ do total de fêmeas coletadas respectivamente.

Palavras chave: Insecta, tripes, hospedeiros, tospovírus, vetor.

\section{ABSTRACT}

\section{Ocurrence of Frankliniella schultzei (Trybom) (Thysanoptera:Thripidae) at weed species}

A monitoring of weeds was carried out on the UNESP Campus in Jaboticabal, SP, with the objective of indentifying host weed species of Frankliniella schultzei (Trybom). The plants were collected weekly and transported to the laboratory inside paper bags. The Berlese funnel method was used to separate the insects from the plants. Thrips were found in

\section{INTRODUÇÃO}

Frankliniella schultzei (Trybom) é um inseto polífago encontrado em várias culturas como, amendoinzeiro, girassol, melancia e soja (Monteiro 1994) e, em plantas daninhas como a falsa serralha (Emilia sonchifolia DC.) (Moscardi \& Almeida, 1980) e artemísia (Ambrosia polyestachya DC.) (Almeida et al., 1994). Além de ter sido encontrado associado as estas plantas, esta praga tem sido constatada na cultura do
19 of the 43 weed species studied: Raphanus sativus L., $R$. raphanistrum L., and Sinapsis arvensis L. presented the highest percentage of thrips, consisting of 45,27 , and $17 \%$ respectively of the total females that were collected.

Key words: Insecta, host plants, thrips, toposvirus, vector.

\footnotetext{
${ }^{1}$ Recebido para pubicação em 11/11/99 e na forma revisada em 17/11/99.

${ }^{2}$ Professora Visitante, DFB/UEPB. CEP: 58100-250, Campina Grande/PB, Brasil.

${ }^{3}$ Professora, FCAV/UNESP. CEP: 14870 -000, Jaboticabal/SP, Brasil.

${ }^{4}$ Aluna de Pós-Graduação em Entomologia ESALQ/USP. CEP: 13418-900, Piracicaba/SP, Brasil.
} 
$50 \%$ da produção, este tripes causa danos diretos atacando hastes, folhas, flores e frutos (Streck 1994).

A única medida recomendada para o controle de $F$. schultzei tem sido o químico. Entretanto, esta tem se mostrado ineficaz, principalmente na região do submédio São Francisco (Ávila et al, 1996). Essa ineficácia pode ser devido ao aparecimento de resistência, pois Boiteux et al., (1993) citam que F. schultzei rapidamente adquire resistência aos inseticidas. Uma vez que as plantas daninhas podem ser reservatório tanto de insetos vetores como de viroses (Duffus, 1971), o manejo das mesmas pode envolver tanto a sua eliminação, quanto o seu uso como plantas armadilha. Essas formas de manejo poderão ser alternativas viáveis para o controle do inseto, a partir da identificação das plantas daninhas hospedeiras, o que se constitui no objetivo desta pesquisa.

\section{MATERIAL E MÉTODOS}

O trabalho foi conduzido na Fazenda de Ensino e Pesquisa da FCAV-Campus de Jaboticabal, no período de 18 de março a 18 de setembro de 1996. O levantamento das espécies de plantas daninhas infestadas com tripes $(F$. schultzei) foi realizado em áreas cultivadas com amendoim, milho, soja, sorgo, aveia, citros (Citrus sinensis L.), goiaba, pêssego, café e macadâmia.

Foram feitas coletas semanais, totalizando-se 28 amostragens. As plantas coletadas foram ensacadas conforme o método de Byerly et al. (1978). Devido ao tamanho diferenciado das plantas daninhas, quando a espécie era representada por um único exemplar coletou-se a planta inteira e, quando por vários exemplares, coletavam-se 4 a 6 partes de 4 a 6 plantas. Nesse caso, as partes coletadas eram as mais tenras (folhas novas, brotos e flores), onde há maior concentração de tripes (Lewis, 1973).

Após a coleta, as plantas foram levadas para o laboratório, colocadas em funil de Berlese por um período de 24 horas. Posteriormente, com auxílio de uma pinça, os tripes foram retirados do funil e conservados em AGA. Os exemplares foram montados em lâminas para identificação em microscópio esterioscópico e, após, etiquetados (Palmer et al., 1989). Como a maioria das chaves de identificação disponíveis é baseada em fêmeas, os machos não foram avaliados. As lâminas estão arquivadas na Coleção Entomológica do Departamento de Defesa Fitossanitária da FCAVJ/UNESP.

\section{RESULTADOS E DISCUSSÃO}

Foram identificadas 43 espécies de plantas daninhas, pertencentes a 16 famílias (Tabela 1). $F$. schultzei ocorreu esporadicamente em 16 das espécies identificadas (42 exemplares) e, com maior frequencia, em mostarda (71 exemplares), nabiça (112 exemplares) e rabanete (186 exemplares) (Tabela 2). Observou-se a presença constante da praga nos meses de abril a setembro nessas brássicas.

A preferência das espécies do gênero Frankliniella pela nabiça tem sido constatada por outros autores. Chellemi et al. (1994) registraram várias espécies como $F$. bispinosa, F. fusca, $F$. tritici e $F$. occidentalis associadas a esta planta. Butin \& Beshear (1995) constataram que na primavera a nabiça é o principal hospedeiro na primavera de $F$. occidentalis e $F$. tritici.

A preferência de tripes em relação aos seus hospedeiros não está bem esclarecida. Alguns trabalhos relatam que as espécies do gênero Frankliniella colonizam mais as plantas em estágio de florescimento (Yudin et al., 1986). Mound \& Teulon (1995) citam que as espécies desse gênero podem colonizar tanto as folhas quanto as flores das plantas. Já Yudin et. al. (1987) constataram que as cores das flores podem influenciar na atratividade de tripes. Os autores sugerem ainda que as cores claras como o amarelo e o branco tendem a atrair mais $F$. occidentalis. Este efeito foi constatado também por Pavan et al. (1993). Os autores observaram que as flores de cor amarelo intenso de tomateiro selvagem propiciou a colonização por F. schultzei. 
TABELA 1. Plantas daninhas presentes no Campus de Jaboticabal/SP.

\begin{tabular}{|c|c|c|}
\hline Nomes comuns & Nomes científicos & Família \\
\hline Amendoim-bravo & Euphorbia heterophylla L. & Euphorbiaceae \\
\hline Angiquinho & Aeschynomene rudis Benth. & Papilionioideaea \\
\hline Anileira & Indigofera hirsuta $\mathrm{L}$ & Fabaceae \\
\hline Apaga fogo & Alternanthera tenella Colla & Amaranthaceae \\
\hline Beldroega & Portulaca oleracea $\mathrm{L}$. & Portulacaceae \\
\hline Bucho-de-rã & Physalis angulata $\mathrm{L}$. & Solanaceae \\
\hline Buva & Conyza bonariensis (L.) Cronq. & Asteraceae \\
\hline Capim-amargoso & Digitaria insularis (L.) Fedde & Poaceae \\
\hline Capim-carrapicho & Cenchrus echinatus L. & Poaceae \\
\hline Capim-colchão & Digitaria horizontalis Willd. & Poaceae \\
\hline Capim-colonião & Panicum maximum Jacq. & Poaceae \\
\hline Capim-marmelada & Brachiaria plantaginea (Link) Hitchc. & Poaceae \\
\hline Capim-pé-de-galinha & Eleusine indica (L.) Gaertn.. & Poaceae \\
\hline Carrapicho-beiço-de-boi & Desmodium tortuosum (Sw.) DC. & Fabaceae \\
\hline Carrapicho-de-carneiro & Acanthospermum hispidum DC. & Asteraceae \\
\hline Caruru-gigante & Amaranthus retrofllexus $\mathrm{L}$. & Amaranthaceae \\
\hline Caruru-rasteiro & Amaranthus deflexus L. & Amaranthaceae \\
\hline Corda-de-viola & Ipomoea grandifolia (Dammer) O'Don. & Convolvulaceae \\
\hline Cordão-de-frade & Leonotis nepetaefolia.(L.) R. Br. & Labiatae \\
\hline Erva-andorinha & Chamaesyce hyssopifolia (L.) Small & Euphorbiaceae \\
\hline Erva-de-santa luzia & Chamaesyce hirta (L.) Millsp. & Euphorbiaceae \\
\hline Falsa-serralha & Emilia sonchifolia. (L.) DC. & Asteraceae \\
\hline Fedegoso & Senna obtusifolia (L.) Irwin \& Barneby & Fabaceae \\
\hline Guanxuma & Gaya pilosa $\mathrm{L}$ & Malvaceae \\
\hline Guanxuma & Sida spinosa $\mathrm{L}$ & Malvaceae \\
\hline Guizo-de-cascavel & Crotalaria incana $\mathrm{L}$. & Fabaceae \\
\hline Joá-de-capote & Nicandra physaloides Gaertn. & Solanaceae \\
\hline Losna-branca & Parthenium hysterophorus $\mathrm{L}$. & Asteraceae \\
\hline Macela & Gnaphalium spicatum Lam. & Asteraceae \\
\hline Malva-branca & Sida cordifolia $\mathrm{L}$ & Malvacea e \\
\hline Malva-estrela & Wissadula subpeltata (O. Kuntze) Fries & Malvaceae \\
\hline Malvastro & Malvastrum sp. & Malvaceae \\
\hline Mamona & Ricinus communis $\mathrm{L}$. & Euphorbiaceae \\
\hline Maria-pretinha & Solanum americanum Mill. & Solanaceae \\
\hline Mentrasto & Ageratum conyzoides $\mathrm{L}$. & Asteraceae \\
\hline Mostarda & Sinapsis arvensis $\mathrm{L}$. & Brassicaceae \\
\hline Nabiça & Raphanus raphanistrum $\mathrm{L}$. & Brassicaceae \\
\hline Pega-pinto & Spergula arvensis $\mathrm{L}$. & Caryophyllaceae \\
\hline Picão preto & Bidens pilosa $\mathrm{L}$. & Asteraceae \\
\hline Poaia-branca & Richardia brasiliensis Gomez & Rubiaceae \\
\hline Rabanete & Raphanus sativus L. & Brassicaceae \\
\hline Tiririca & Cyperus rotundus $\mathrm{L}$. & Cyperaceae \\
\hline Trapoeraba & Commelina benghalensis L. & Commelinaceae \\
\hline
\end{tabular}


TABELA 2. Número de fêmeas de Frankliniella schultzei associadas às plantas daninhas identificadas como hospedeiras.

\begin{tabular}{lcccccccr}
\hline \multirow{2}{*}{\multicolumn{1}{c}{ Plantas Daninhas }} & \multicolumn{7}{c}{ Tripes $^{\mathrm{a}}$} \\
\cline { 2 - 8 } & Março & Abril & Maio & Junho & Julho & Agosto & Setembro & Total \\
\hline Amendoim-bravo & - & 0 & 0 & 0 & 1 & 0 & 0 & 1 \\
Bucho-de-rã & 0 & 2 & 0 & 0 & 3 & 0 & 0 & 5 \\
Carrapicho-beiço-de-boi & - & 0 & 0 & 0 & 1 & - & 0 & 1 \\
Capim-carrapicho & 0 & 0 & 0 & 0 & 0 & 2 & 0 & 2 \\
Capim-colonião & - & 0 & 0 & 2 & 1 & 1 & 0 & 4 \\
Caruru-rasteiro & 0 & 0 & 5 & 0 & 0 & 0 & 1 & 6 \\
Corda-de-viola & - & 0 & 1 & 0 & 0 & 0 & 0 & 1 \\
Erva-de-andorinha & - & 0 & 0 & 0 & 1 & - & 0 & 1 \\
Falsa-serralha & - & - & - & 0 & 3 & 0 & 5 & 8 \\
Guanxuma. & 0 & 0 & 3 & 0 & 0 & 0 & 0 & 3 \\
Guizo-de-cascavel & 0 & 0 & 0 & 0 & 1 & 1 & 0 & 2 \\
Juá-de-capote & - & - & - & - & 1 & - & - & 1 \\
Malva-estrela & - & - & - & 0 & 1 & 0 & - & 1 \\
Maria-pretinha & - & 0 & 0 & 0 & 0 & 3 & 0 & 3 \\
Mentrasto & - & - & - & 0 & 0 & 1 & - & 1 \\
Mostarda & - & 10 & 24 & 11 & 14 & 10 & 2 & 71 \\
Nabiça & - & 14 & 16 & 28 & 27 & 6 & 21 & 112 \\
Picão-preto & 0 & 0 & 0 & 0 & 0 & 2 & 0 & 2 \\
Rabanete & - & 35 & 72 & 11 & 14 & 31 & 23 & 186 \\
\hline Total & & & & & & & & 411 \\
\hline
\end{tabular}

Número total mensal de fêmeas.

(-) Ausência da espécie de planta daninha.

Esta argumentação de que as cores das flores pode influenciar na atratividade do tripes concorda com os resultados obtidos em mostarda, rabanete e nabiça, que apresentaram as cores amarela, lilás e branca, respectivamente. Porém este fato não mostrou-se tão evidente quando comparado com algumas plantas como o apagafogo, buva, losna-branca e a malva-branca, fedegoso e pega-pinto que apresentaram as cores branca e amarela, respectivamente, que não foi constatada a presença de $F$. schultzei.

Os resultados mostraram que as brássicas (rabanete, nabiça e mostarda) foram as que apresentaram as maiores porcentagens de $F$. schultzei, 45,27 , e $17 \%$ do total das fêmeas coletadas, respectivamente.

\section{Agradecimentos}

Os autores agradecem a $\operatorname{Prof}^{\mathrm{a}} . \operatorname{Dr}^{\mathrm{a}}$ Maria do Carmo Morelli Damasceno Pavani, o técnico agrícola Gilson José Leite pela identificação das plantas daninhas e ao auxiliar de laboratório Dionisio Celso de Figueiredo Neto pela ajuda nas preparações das lâminas.

\section{LITERATURA CITADA}

ALMEIDA, A. M. R., NAKAHARA, S., SOSAGOMEZ D. R. Thrips species identified in soybean fields in Brazil. An. Soc. Entomol. Brasil, v.23, n.2, p.363-365, 1994. 
AMIN, P. V., REDDY, D. V. R., GHANEKAR A. M. Transmission of tomato spotted wilt virus, the causal agent of bud necrosis of peanut by Scirtothrips dorsalis and Frankliniella schultzei. Plant. Dis., v.65, p.633-665, 1981.

ÁVILA, A. C., LIMA, M. F., RESENDE, R. O., POZZER L., FERRAZ, E., MARANHÃO, E. A. A., CANDEIA, J. A., COSTA, N. D. Identificação de toposvírus em hortaliças no Submédio São Francisco utilizando DASElisa e DOT-Elisa. Fitopatologia Brasileira, v.21, p.503-507,1996.

BOITEUX, L. S., GIORDANO, L. B., ÁVILA, A. C., SANTOS, J. R. M. Tsw-10: linhagem de tomate para mesa resistente a três espécies de tospovirus causadoras do vira-cabeça. Hort. Bras., v.11, p. 163-164, 1993.

BUTIN, G. D., BESHEAR. R. J. Seasonal abundance of thrips (Thysanoptera) on winter small grains in Georgia. Environ. Entomol., v. 24, n.5, p.1216-1223, 1995.

BYERLY, K. F., GUTIERREZ, A. P., JONES, R. E., LUCK, R. F. A comparison of sampling methods for some arthropod populations in cotton. Hilgardia, v. 46, n.8, p.257-282, 1978.

CHELLEMI, D. O., FUNDERBURK, J. E., HALL, D. W. Seasonal abundance of flower-inhabiting Frankliniella species (Thysanoptera: Thripidae) on wild plant species. Environ. Entomol., v.23, n.2, p.337-342, 1994.

DUFFUS, J. E. Role of weeds in the incidence of virus diseases. Annu. Rev. Phytopatol., v.9, p. 319-340, 1971.

GONDIM, D. M. C. ; BELOT, J. L.; MICHEL, B. Manual de identificação das pragas, doenças, deficiências minerais do algodoeiro no Estado do Paraná. Cascavel: GCEPAR/CIRAD-CA, 1993. 100p. (GCEPAR. Boletim Técnico,33).

LEWIS, T. Sampling, In: LEWIS, T. Thrips: their biology, ecology and economic importance. New York: Academic Press, 1973, p.101-128.

MONTEIRO, R. C. Espécie de thrips (Thysanoptera, Thripidae) associadas a algumas culturas no Brasil. Piracicaba: ESALQ/USP, 1994, 85p. Dissertação de Mestrado.

MOSCARDI, F., ALMEIDA, A. M. R. Ocorrência de espécies de tripes soja e outras plantas hospedeiras, comumente associadas a esta cultura, no estado do Paraná. EMBRAPA - CNPSo. Res. Pesq. Soja. 1980. p.169-71.

MOUND, L. A., TEULON, D. A. Thysanoptera as phytophagous opportunist. In: PARKER, B. L., eds. Thrips biology and management, Londres: Plenum Press, 1995, p.3-20.

PALMER, J. M., MOUND, L. A., HEAUME. G. L. Thysanoptera, CAB, (CIE guides to insects of importance to man, 2). 1989, 74p.

PAVAN, M. A., COSTA, A. S., KUROZAWA, C., FORTI, L. C., GUIMARÃES, A. M. Colonização do tomateiro e de ervas daninhas pelo tripes vetor do vírus do viracabeça do tomateiro. Hort. Bras., v.11, n.2, p.122-125, 1993.

STRECK, A. A. Ocorrência e ação de insetos prejudiciais em diferentes cultivares de hortaliças em Cachoeira do Sul, RS. Cachoeira do Sul : Faculdade de Filosofia Ciências e Letras, 1994. 67p.

YUDIN, L. S., MITCHELL, W. C. CHO J. J. Color preference of thrips 
(Thysanoptera: Thripidae) with reference to aphids (Homoptera: Aphididae) and leafminers in Hawaiian lettuce farms. J. Econ. Entomol., v. 80, n. 1, p. 51-55, 1987.
YUDIN, L. S., TABASHINIK, B. E., CHO, J. J., MITCHELL,. W. C. Colonization of weeds and lettuce by thrips (Thysanoptera: Thripidae). Environ. Entomol., v. 17, n.3, p.522-26, 1988. 